\title{
APROXIMACIONES AL PROCESO DE EXPANSIÓN URBANA EN CIUDADES INTERMEDIAS \\ El caso del municipio de Río Grande en el período 2005-2015
}

\author{
Finck, Nadia Belén \\ Instituto de Cultura, Sociedad y Estado (ICSE), Universidad Nacional de Tierra del Fuego (UNTDF), Onas \\ 450, 9410, Ushuaia, Argentina - Consejo Nacional de Investigaciones Científicas y Técnicas (CONICET) \\ Director de la tesis en curso: Dra. María Cristina Cravino \\ EMail: fincknadia@gmail.com - nfinck@untdf.edu.ar
}

\section{RESUMEN}

La participación de las ciudades intermedias en el sistema urbano argentino es muy relevante, tanto en términos cuantitativos como cualitativos. Estas han evidenciado un crecimiento demográfico y espacial en las últimas décadas tendencialmente con baja densidad. La relevancia empírica de las ciudades intermedias en Argentina sin embargo, no se ve reflejada en el campo de estudios urbanos, aunque recientemente y a partir de la expansión del sistema científico, han comenzado a emerger diferentes estudios de casos. En este sentido, a partir del análisis de -la Ciudad de Río Grande, en la Patagonia Argentina, en el periodo 2005-2015-, nos proponemos abordar los procesos recientes de transformación urbana, los actores intervinientes allí y en particular la localización y calidad urbana diferenciada que emergió como resultante. Es decir, nos interesa comprender la producción de ciudad que conlleva procesos de distribución desigual de los bienes urbanos socialmente valorados.

Palabras clave: Ciudades Intermedias. Crecimiento urbano. Estado municipal

\begin{abstract}
In the Argentinian urban system, the Intermediate Cities are relevant both quantitatively and qualitatively.In fact, these cities have grown according to a process of expansion with low density. Although, there is no evidence of the existence any relevant social studies addressing the urban issue and focusing into Intermediate Cities, cases studies have progressively rise. In this way, it is the aim of this paper to approach the recent process of urban transformation of the city of Rio Grande in the Argentininian Patagonia between 2005 and 2015, and the its participants as well as to analyze the city production that brings about unequal distribution processes of socially valued urban properties.
\end{abstract}

Key words: Intermediate cities. Urban development. Local government 


\section{INTRODUCCIÓN}

El presente trabajo, que forma parte de los primeros abordajes de investigación realizados en el marco de los estudios de Doctorado en Geografía ( $P h D$ en Geografía) (Universidad de Buenos Aires), tiene por objetivo, a partir de un caso, analizar el crecimiento de una ciudad intermedia en el periodo 2005-2015, y las políticas de gestión urbana municipal. Estas últimas serán comprendida en el marco de condicionalidades de las políticas provinciales y nacionales, lo que implica a su vez considerar las relaciones entre ellas.

El trabajo se enmarca en un abordaje más general que propone como objetivo, contrastar la producción teórica sobre crecimiento urbano con los datos empíricos relevados y ver su fertilidad en estos contextos. Un aspecto que nos interesa profundizar es la comprensión teórica de la articulación y disputa de actores en la producción de ciudad. En este marco, la hipótesis a sostener es que, en las áreas de expansión es posible identificar, respecto de los procesos de producción urbana, las preponderancias de lógicas de producción de ciudad, que produce localización diferenciada y por lo tanto una distribución desigual de los bienes urbanos socialmente valorados (Soja, 2014). Recupera, asimismo, teorizaciones sobre la producción social del espacio (Bourdieu, 2013) (Harvey, 2016) (Lefebvre, 2013) (Soja, 2016) (Abramo, 2008) (Pirez, 1995). Metodológicamente, se trata de un estudio de caso, que se abordará desde técnicas de investigación cualitativa y que recurrirá tanto a fuentes primarias como secundarias.

Entendemos que el caso de estudio planteado, sobre la ciudad de Rio Grande, ubicada en la zona norte de la isla grande de Tierra del Fuego, en el extremo austral de la Patagonia argentina, abona los abordajes sobre ciudades intermedias en el país. En particular nos interesa analizar: a) las características del proceso de crecimiento demográfico, b) la vinculación entre el crecimiento demográfico y el crecimiento espacial de la ciudad y c) las características que asume el crecimiento espacial: discontinuidades, densidades, perfiles socioeconómicos, tipología habitacional de la vivienda de interés social, villas y asentamientos o loteos formales (Atlas ID, 2015). Estos elementos descriptivos se articularán con el análisis de las políticas urbanas locales para comprender sus articulaciones y sus vínculos con las estrategias de los actores transformadores de la ciudad.

Entendemos que la ciudad se produce a partir de procesos sociales, con actores diversos en tensión y con desiguales capacidades de incidencia. Abramo (2008) plantea que en las ciudades existen tres "lógicas de coordinación social de acceso al suelo urbano"; desde esta perspectiva, considera al Estado y el mercado como formas convencionales de acceso a la ciudad, en base a instituciones apoyadas en un marco normativo. La tercera lógica, la de "la necesidad", es aquella a través de la cual se resuelve el acceso al hábitat por fuera del -o por lo menos sorteando el- marco normativo. Es decir, dentro de la trama de un mercado informal, que sobrepasa la regulación institucional y los controles tradicionales propios del estado y del derecho aunque, como advierte Bachiller (2015), en muchas situaciones existan modos informales de regulación estatal.

El acceso a la ciudad bajo esta lógica de necesidad, muchas veces, se presenta como la única opción posible. Cravino y Fernández Wagner (2006:1), afirman al respecto que muchas familias logran satisfacer la necesidad de vivir en la ciudad, a partir de "un espectro de situaciones, que abarcan desde mercados informales del suelo (por la vía de intermediarios), hasta situaciones de hecho. Por eso, la ocupación irregular de tierras y el asentamiento en áreas sin servicios, ambientalmente degradadas, o expuestas a desastres naturales, es el modo predominante de acceso a la ciudad, de parte de los sectores más pobres de la población".

En este trabajo hacemos referencia a la modalidad de producción de ciudad, vivienda y hábitat por autoproducción, que asume la característica según Rodríguez et al (2007) de realizarse bajo la iniciativa y control de los propios usuarios, individual (formas como la ayuda mutua) y/o familiar (a través de grupos informales o asociaciones organizadas para tomar, solicitar o comprar tierra y gestionar servicios e infraestructura) y/o comunitaria-colectiva y organizadamente (como cooperativas). Frente a la autoproducción del hábitat, muchas veces el Estado en apariencia de la imposibilidad de desarrollar otro tipo de políticas, como afirma Smolka (2003:3), se posiciona en el lugar de 'tolerar las 'soluciones' informales para posibilitar el acceso a la tierra y después normalizar o 'desmarginizar' los asentamientos, como algo más barato en el largo plazo para los fondos públicos y mejor para los ocupantes de bajos ingresos". 
Al referirse a "otro tipo de políticas" se está interpelando la producción de vivienda social y suelo urbano servido, que muchas veces por ser muy costosa en su modalidad tradicional, pareciera inviable. En América Latina, esas políticas tradicionales se caracterizaron tradicionalmente por girar en torno a tres ejes, como explica Maldonado (2009:327):

"a) la construcción estatal de vivienda, b) el otorgamiento de subsidios directos a la demanda en programas generalmente desarrollados por el sector privado o por una combinación de actuaciones público-privadas en las que se subsidia el acceso a la vivienda como producto terminado y c) los programas paliativos de regularización de asentamientos de origen informal y de mejoramiento barrial".

Esta situación contrasta con los relativos avances en materia de desarrollo e implementación de instrumentos de gestión y regulación urbanística que proponen alternativas en la gestión de la tierra urbana, partiendo de entenderla como una herramienta fundamental para el desarrollo socio-económico de las ciudades en dirección a un proceso sustentable (Reese, 2011). En el caso de Río Grande, es notorio el rol que adopta el Estado local en materia de política urbana y habitacional, en particular en el periodo 20112015, donde combinó acciones de políticas tradicionales con alternativas de gestión de la tierra urbana. Aun así, las intervenciones realizadas en la ciudad en torno de esas políticas se localizaron en lugares distintos de la ciudad como veremos en el desarrollo del presente trabajo.

En las conclusiones del trabajo se recuperan las principales características destacadas del periodo analizado: la ciudad de Rio Grande, en términos generales tendió a expandirse con baja densidad y de manera discontinua. En las áreas de expansión, las acciones en materia de producción de vivienda de interés social por parte del estado, se localizaron preponderantemente en la zona oeste de la ciudad. Por su parte, en el norte se concentraron nuevas urbanizaciones de la mano de desarrolladores inmobiliarios privados o bien a través de estrategias público-privadas. En la zona sur, por otro lado, son los tejidos residenciales de asentamientos los que participan mayoritariamente; al respecto el Estado local primero mantuvo una postura de tolerancia y posteriormente de mejoramiento progresiva.

\section{CIUDADES INTERMEDIAS}

Argentina, que ha sido uno de los países más tempranamente urbanizados en América Latina, posee un sistema urbano compuesto por unas pocas grandes ciudades y un gran número de ciudades intermedias y pequeñas. Más del $90 \%$ de la población vive en áreas urbanas, aun así, esa población no está distribuida de manera homogénea en el país, sino que se ha configurado un sistema urbano caracterizado por una sostenida primacía y una disminución de la macrocefalia (Vapñarsky, 1995), hecho que se ejemplifica con la disminución del predominio de Buenos Aires desde el punto de vista de la concentración urbana (Erbiti, 2007).

Por otro lado, autores como Manzano y Velázquez (2015:274) sostienen como principales tendencias del sistema urbano argentino de los últimos 40 años, "el descenso de la población dispersa, la participación de los aglomerados menores de 50.000 habitantes y el crecimiento de la población residiendo en aglomeraciones de tamaño intermedio (ATI's) que, de acuerdo a la clasificación basada en el criterio demográfico de cantidad de habitantes (Vapñarsky y Gorojovsky, 1990), son aquellas que implican entre 50.000 y 999.999 habitantes.

Si bien resaltamos aquí la dimensión demográfica como parámetro relevante en la clasificación de las ciudades, no desconocemos aquellos elementos que resultarían relevantes incorporar para distinguir a las ciudades en el conjunto del sistema urbano en general, haciendo referencia con ello a lo ya anotado por Bellet y Llop (2004:2) respecto de las funciones que estas ciudades desarrollan: mediación en los flujos () entre territorios urbanos y rurales de su área de influencia y otros centros o áreas más alejados y funciones de intermediación entre espacios locales/territoriales y espacios regionales/nacionales/globales.

El crecimiento de las ciudades intermedias en Argentina es un proceso sostenido desde mediados del siglo $\mathrm{XX}$ aunque se pronunció hacia los años $90^{\prime}$. Para el caso de los últimos años, el número de aglomerados de este rango aumentó de un total de 63 ATl's en 2001 a 67 en 2010 (INDEC) y dicho incremento se localizó en la región del Noreste y Patagonia. En esta última región, el crecimiento poblacional superó ampliamente al nacional: por solo citar un caso, la tasa de crecimiento anual medio para Tierra del Fuego Antártida e 
Islas del Atlántico Sur (AIAS), fue para el periodo 1991-2001 de 37,8 (0/00), y para el periodo 2001-2010 fue de $28,8(0 / 00)$, dicha tasa para el total país fue del $12,8(0 / 00)$ y $10,5(0 / 00)$ para cada periodo respectivamente.

Las ciudades fueguinas también crecieron en términos espaciales. En el caso de Río Grande la mancha urbana creció un $85 \%$ entre 2006 y 2016 aunque no sucedió lo mismo con la densidad poblacional que al contrario tendió a bajar: ajustada a la mancha urbana, la misma se redujo de 5232 (h/km2) en 2010 a 3770 (h/km2) en 2016 (Martínez, 2017). Según el estudio que citamos, "el crecimiento es discontinuo, con saltos en la urbanización, dejando amplios espacios sin urbanizar (vacíos urbanos)" (Martínez, 2017:65).

Es importante destacar aquí que los usos de suelo de carácter residencial, no residencial (clasificados según su naturaleza: uso de servicio terciario (hotel, grandes superficies comerciales, servicios generales y oficinas, etc.), uso equipamiento colectivo (deportivo, social, plazas, parques y espacios verdes públicos, etc.), etc.) y mixto (Plan urbanístico, titulo II, Capítulo V; Ordenanza $N^{\circ} 2863,2011$ ), se concentraron en la margen norte del Rio Grande que atraviesa la ciudad. Aquí se ubica, por un lado, el aeropuerto que genera un espacio disruptivo de tamaño considerable, teniendo en cuenta además las zonas de protección y por otro un cantón militar (Batallón de infantería). Las actividades económicas que dinamizaron el territorio hasta la mitad del siglo XX se concentraron en la margen sur de dicho río. En esta última zona proliferaron los usos residenciales recién en 1980 y en 2005 se produjo un nuevo impulso de crecimiento relevante a partir de una serie de ocupaciones que dieron origen a nuevos barrios en asentamientos populares (bajo la lógica de la necesidad de acuerdo a Abramo (2008)).

\section{RÍO GRANDE: DE COLONIA AGRICOLA A CIUDAD INTERMEDIA}

La ciudad de Río Grande se encuentra emplazada en la zona norte de la isla grande de Tierra del Fuego, sobre una llanura con algunas elevaciones y sobre la costa del océano Atlántico. El aglomerado se asentó sobre las márgenes de un curso de agua de igual nombre (Río Grande) que nace en la cordillera y desemboca en el mar, atravesando a la mancha urbana desde el oeste al este. En la actualidad tiene una superficie de $25,8 \mathrm{~km} 2$ y una población estimada de 95.463 habitantes, una densidad de 3700 habitantes por kilómetro cuadrado. Al año 2010, el déficit habitacional fue de un $27,4 \%$ y un déficit de infraestructura de $4,6 \%$ en lo que respecta al acceso de los hogares al agua por red pública. Asimismo, se calculó que el $16,9 \%$ de los hogares se encontraban en situación de irregularidad respecto de la tenencia de la tierra. (Municipio de Río Grande, 2017).

En sus orígenes, hacia fines del siglo XIX, en la margen sur del Rio Grande se asentaron las actividades agropecuarias mientras que los primeros habitantes no indígenas (religiosos y trabajadores inmigrantes) fueron poblando poco a poco la margen norte del río. La ciudad tuvo desde entonces un rol importante en la región sur-sur de la Patagonia argentino-chilena en el marco del modelo agroexportador argentino.

Gráfico 1. Imagen de ubicación de ciudad de Río Grande, Provincia de Tierra del Fuego, Antártida e Islas del Atlántico Sur, Argentina 


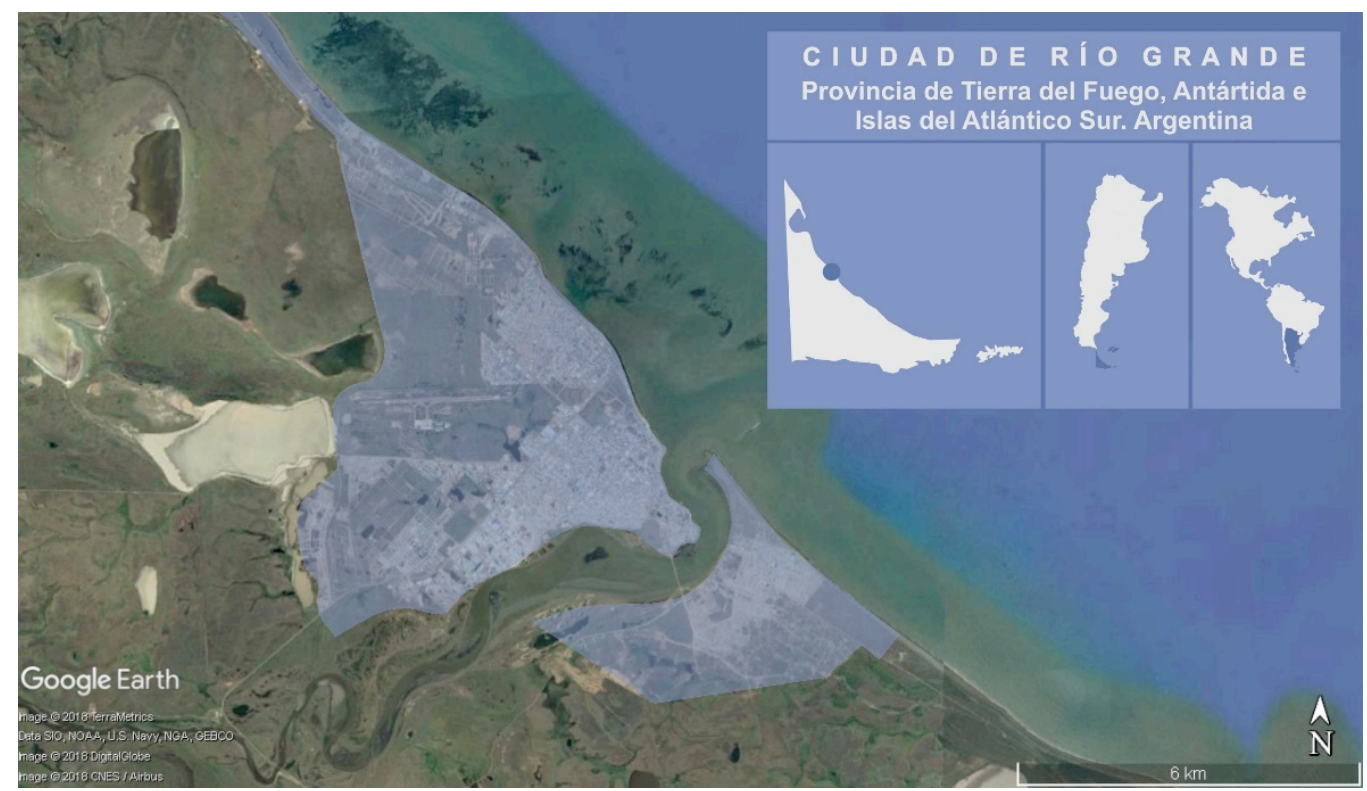

Fuente: elaboración propia en base a imagen Google Earth 2018

La región patagónica argentina fue incorporada al estado nacional tras los procesos de ocupación e institucionalización luego del despliegue de expediciones financiadas por el proceso de "pacificación" del país y el desarrollo económico (Cao y Vaca, 2006). A este periodo (1880-1930), autores como Bustos Cara (2002), se lo denomina como "etapa de estructuración" del sistema territorial moderno liberal o "primera modernización". Esa incorporación dependiente del poder central fue en carácter de "territorio nacional".

En ese contexto, en el año 1921, mediante un decreto del presidente Hipólito Yrigoyen se fundó la Colonia agrícola y pastoril de Río Grande. Sin embargo, el acto administrativo reconoció entonces el carácter que el asentamiento espontaneo ya había adquirido al menos treinta años antes y que fue configurándose con características urbanas (Maveroff, 1979). Ello se inscribe en el impulso del modelo agroexportador que promovió en la región patagónica la radicación de actividades vinculadas a la producción ovina de merino que se había trasladado desde la Pampa húmeda, las Islas Malvinas y Punta Arenas hacia la Patagonia austral (Bandieri, 2000).

El proceso de ocupación estuvo caracterizado por un modelo de "expansión territorial con bajo poblamiento" como explica Bandieri (2006:3-4), dado el requerimiento de "expandir a suelos marginales la ganadería extensiva en sus distintos rubros, pero particularmente ovino y la inversión especulativa en tierras". En el caso fueguino se destaca la altísima concentración de la tierra: en la zona norte de la isla grande de Tierra del Fuego, hacia 1915, la tierra se distribuyó en al menos cinco grupos privados: Braun, Menéndez Behety, Montes, Cullen y Bridges \& Reynolds. La mayor cantidad de tierras se encontraban en manos de Menéndez (Bou, 1995).

En 1918 José Menéndez -un empresario español radicado en Punta Arenas (Chile) desde 1874 (Alonso Marchante, 2014)- instaló un frigorífico de la Compañía Frigorífica Argentina de Tierra del Fuego, en propiedades que había adquirido en la margen sur del rio grande ya en 1893 (estancia Primera Argentina). Estas innovaciones dinamizaron el territorio al que llegaron desde entonces nuevos habitantes para trabajar en las distintas actividades vinculadas y en aquellas que la dinámica de una ciudad en crecimiento demandaba.

Desde el Gobierno fueguino, en 1928, se aprobó una disposición -ratificada por el poder central nacional unos meses más tarde-, a partir de la cual se creó la primera Comisión de Fomento en la localidad. Es decir que se delegó la administración de los intereses locales en un grupo de personas (cinco en total que eran los principales comerciantes de aquel entonces (Gutiérrez, 2001)), quienes tomarían algunas decisiones delegadas hasta el reconocimiento de mayor autonomía institucional.

A partir de 1968 Tierra del Fuego fue declarada "territorio prioritario" para el Estado Nacional (Imaz, 1972), es decir, un objeto de intervención estatal privilegiado por ejemplo, en materia de proyectos de desarrollo. 
En ese contexto es que se produjo un aumento significativo de la población. En particular ese crecimiento fue exponencial a partir de 1970 cuando se diseñó e implementó un régimen de promoción aduanera y fiscal, establecido a partir de la sanción de la Ley Nacional 19.640 (año 1972). El factor explicativo de dicho crecimiento estuvo dado principalmente por los flujos migratorios de otras provincias de argentina (Hermida, Malizia y Van Aert, 2013).

El nuevo estatus jurídico sobre el territorio fueguino fue exitoso en sus objetivos: promover la radicación de empresas y, con ello, de población -argentina- en un área de interés geopolítico para el país, por la cercanía con la Antártida y las Islas Malvinas, éstas últimas ocupadas de manera ilegítima por Gran Bretaña desde 1833. A esto se agrega una serie de litigios fronterizos con Chile, que llegaron incluso a derivar en hipótesis de conflicto bélico a fines de 1970. Las migraciones, prioritariamente internas, se mantuvieron constantes, aunque nunca más con el vigor que existió entre las décadas de 1970 y 1990, como se observa en el siguiente gráfico (gráfico 2).

Gráfico 2. Gráfico de población total urbana, Rio Grande (Pcia. De Tierra del Fuego AIAS)

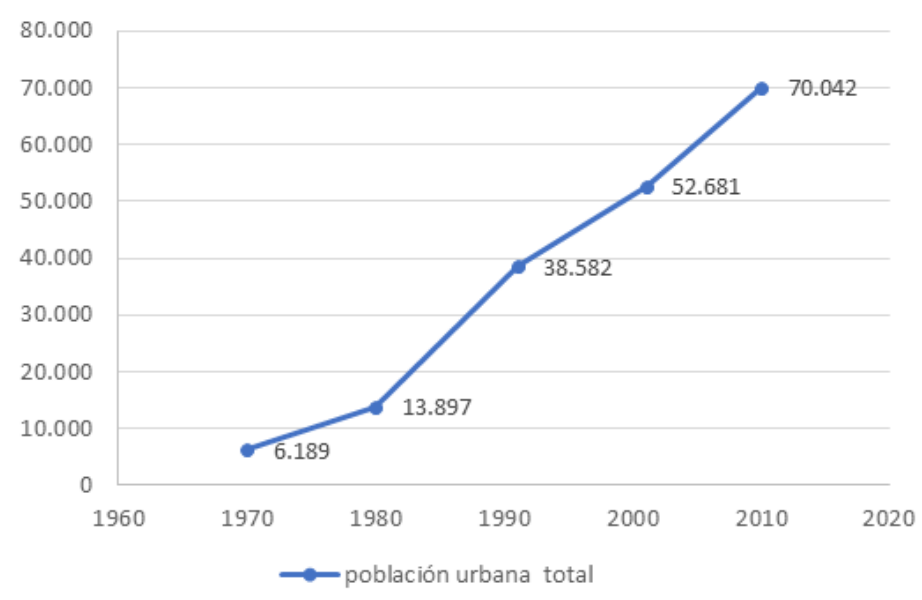

Fuente: elaboración propia en base a censos 1970. 1980, 1990, 2000 y 2010 (INDEC).

El crecimiento sostenido de la población, la desregulación del mercado inmobiliario y la ejecución de políticas de producción de vivienda y acceso al suelo urbano de carácter tradicional, devinieron en una situación de restricción en el acceso al suelo y la vivienda. En los últimos veinte años, en materia de producción de suelo y vivienda, uno de los hechos más significativos fue el proceso de ocupación que se produjo a partir del año 2005 como se ha mencionado, a partir de una serie de tomas de tierra -tanto en Ushuaia, capital de la provincia como en Río Grande-, que pusieron en la agenda pública la cuestión habitacional. El tema del acceso a la vivienda se posicionó como una cuestión socialmente problematizada (Ozslak y O'donnell, 2011), lo que implicó el diseño e implementación de una serie de leyes provinciales y ordenanzas municipales que reconocieron la situación de crisis urbano-ambiental y pretendieron actuar en consecuencia para morigerarla.

En el caso que nos ocupa, esos procesos de ocupación se localizaron en la zona sur de la ciudad promoviendo un proceso de expansión en esa dirección, a contrapelo de lo establecido en el Plan de Desarrollo Territorial finalizado también en 2005. Se trató en efecto de un proceso de "producción de ciudad inverso a la planificación formal" donde "a la ocupación de hecho le siguió la lucha por la regularización dominial y la consolidación de la infraestructura barrial" (Del Rio y Duarte, 2011:134). A su vez, el estado local a partir de estos mismos años se hizo de herramientas con las cuales aumentó su capacidad de intervención en materia de políticas urbanas (Del Rio, Vertiz y Ursino, 2014). Ahondaremos sobre este aspecto en el próximo apartado. 


\subsection{EL ROL DEL ESTADO LOCAL EN UNA CIUDAD INTERMEDIA}

La Provincia de Tierra del Fuego, Antártida e Islas del Atlántico Sur adquiere rango de provincia, es decir se autonomiza jurisdiccionalmente del poder central en el año 1990, a partir de la Ley Nacional $N^{\circ} 23775$. Este nuevo estatus habilitó a sus habitantes a dictarse de manera autónoma una propia Constitución Provincial, lo que ocurrió en 1991. La constitución sancionada entonces reconoció la plena autonomía de los municipios que, como en el caso de Río Grande, contaran con más de 10.000 habitantes (Articulo 170 y 171, Constitución de la Provincia de Tierra del Fuego, AIAS (CP-TDFAIAS, 1991)). Este hecho consolidó un proceso de autonomización que había iniciado en 1980 a partir de la Ley Territorial de Municipalidades ( $\mathrm{N}^{\circ} 236$, año 1984). Como es posible advertir, en este territorio los municipios son preexistentes a la provincia.

En 1997 el municipio creó una Dirección de Tierras, para asumir, entre otras, la responsabilidad de "distribuir la tierra fiscal" (CP-TDFAIAS) traspasada a los municipios luego que el poder ejecutivo nacional hiciera lo mismo con la provincia (Finck, 2016). En los años 2000 se puso en vigencia un "Esquema de ordenamiento del territorio" y entre 2002 y 2005, se elaboró el Plan de Desarrollo Territorial (Código Urbanístico), el que finalmente fue sancionado como ordenanza municipal y que adquirió plena vigencia en 2011.

En el año 2006 se sancionó la Carta Orgánica Municipal (COM) -aún vigente- que estipula una serie de atribuciones no delegadas, que el estado local se reserva para sí como ser la planificación de la política de vivienda en coordinación y concurrencia con otros niveles de estado, organismos internacionales y la iniciativa privada de acuerdo a una serie de principios. A su vez, estipula cuestiones de relevancia como ser el desaliento de la especulación inmobiliaria (Articulo 63, COM; 2006).

La dilación de seis años que existió para aprobar el Código de Planeamiento o Plan de Desarrollo Territorial (PDT) puede ser interpretada de distintas maneras. Algunos informantes clave del Poder Ejecutivo y Legislativo riograndense se refirieron a la "falta de acuerdos" entre ambos poderes. Una serie de cuestiones debieron modificarse antes de su aprobación, como ser algunos planos que identificaban en la ciudad construida la zonificación asignada que debió incorporar la ciudad construida en esos seis años. Las tensiones manifiestas entre poderes del Estado también se produjeron entre actores productores de ciudad guiados por diferentes lógicas, que disputaron transformaciones en la norma aprobada: la ordenanza sufrió diez modificaciones en el primer año de vigencia.

EI PDT incluyó una serie de instrumentos de gestión y regulación urbanística, que son esenciales en la gestión de la tierra urbana en la medida que inciden directamente en la construcción y configuración del territorio" (Reese, 2011). De acuerdo a Bervejillo (2009) citado en Basualdo (2016), un instrumento es "un dispositivo más o menos estandarizado, apto para ser utilizado en distintas situaciones con objetivos específicos como parte de una actuación o de una estrategia". Algunos de los instrumentos definidos en 2005 se pondrían en vigencia recién entre los años 2012 y 2015. En efecto, se produjo un viraje en el accionar municipal en tanto actor productor de ciudad (Pirez, 1995) (Abramo, 2008): el municipio innovó en materia de política de vivienda y tierra: como mencionamos puso en marcha la aplicación de algunos de los instrumentos incorporados en el PDT, como ser la asociación público-privada para garantizar la oferta de suelo urbano servido a partir de un sistema de financiamiento para familias con capacidad de ahorro (ordenanza municipal $\mathrm{N}^{\circ} 3287,2014$ ) o instrumentos de captación de plusvalías como ser el de contribución por mejoras (ordenanza municipal $\mathrm{N}^{\circ} 2934$, 2011). A su vez, también ejecutó programas interjurisdiccionales, construyendo por primera vez en la historia, barrios de vivienda social, a la vez que desarrolló estrategias de urbanización de asentamientos y de regularización dominial, acciones que también fue realizando en simultáneo el gobierno provincial.

Hemos dado cuenta de la construcción del importante andamiaje normativo que fue robusteciendo la capacidad municipal en materia de producción de ciudad. Reconocemos en ese viraje, dado en 2011 , la demarcación de un rumbo distinto en el rol del estado local. Por un lado, modifica la tendencia que identificamos respecto de la desregulación del mercado inmobiliario a partir de, por ejemplo, la puesta en marcha del mecanismo de captación de plusvalías urbanas. Por otro lado produce barrios de viviendas de interés social y se involucra en las políticas de urbanización de asentamientos en la zona sur.

De esta manera notamos que el rol que asumió el estado local en el periodo de estudio (2005-2015) no fue homogéneo, aunque los rasgos generales de la cuestión urbana se presentaron como acuciantes durante 
todo el periodo y de manera incremental ya desde 2001. Desde ese momento, coincidente con una profunda crisis económica social nacional, sucedieron algunas transformaciones urbanas negativas: aumento del déficit cuantitativo y cualitativo, disminución de los propietarios y aumento de los inquilinos entre otros (Pérez y Martínez, 2014) (Martínez, Finck, Lobato et al, 2017). Ahora bien, nos interesa profundizar, en el marco del proceso de crecimiento de la ciudad, sobre las características que ese crecimiento tuvo a nivel general para luego focalizar sobre las huellas urbanas del accionar del estado local en vinculación con las otras dos formas de producir ciudad.

\section{CARACTERÍSTICAS DEL CRECIMIENTO DE RÍO GRANDE: 2005-2015}

En este último apartado pretendemos presentar las características generales del proceso de crecimiento urbano del periodo 2005-2015, para lo cual se tomarán una serie de indicadores propuestos por el Ministerio de Planificación Federal, Inversión Pública y Servicios (2015) publicados en el ATLAS ID donde se comparan un total de 21 conglomerados urbanos de distinta jerarquía y posición en el sistema urbano argentino. Entendemos que estos datos tienen importancia, no solo porque en algunos casos no existen antecedentes en el país, sino también porque al comparar ciudades, permiten identificar las particularidades del caso riograndense. Seguidamente nos centramos en identificar las preponderancias existentes en las áreas de expansión de acuerdo a las grandes zonas (norte, oeste y sur) en lo que respecta a tejidos residenciales y con ello, a los actores participantes.

La producción de suelo urbano y vivienda de interés social por parte del estado adquiere en el periodo un lugar de importancia. A inicios de 2005, el gobierno provincial, anuncia el inicio de obra de la construcción de 1017 viviendas en el oeste de la ciudad a partir de los Programas Federales de Vivienda reactivados a partir de 2003 (Rodríguez, 2010) (Rodulfo, 2015). Estos se proyectaron en un predio que no poseía en ese momento continuidad con los tejidos residenciales ya existentes. Dos años más tarde (2007) el municipio haría entrega de lotes sin la totalidad de servicios en la urbanización que proyectó en la misma zona oeste (Chacra XI) aunque alejada de la urbanización provincial (Chacra XIII, denominada en la actualidad como "Barrio Malvinas Argentinas"), tal como se observa en la gráfico 3.

En 2014, el municipio hizo entrega de las primeras 50 viviendas del primer barrio de gestión municipal (suelo urbano y vivienda): Barrio Los Cisnes. Ese mismo año desde el ejecutivo local anunciaron el desarrollo de una estrategia de actuación público-privada mediante la cual a partir de un fideicomiso, se ofertan a un menor costo que en el mercado inmobiliario, unos 1800 lotes con servicios a ser entregados a dos años del inicio de la operatoria. Al mes de marzo de 2018 la entrega aún no se había concretado.

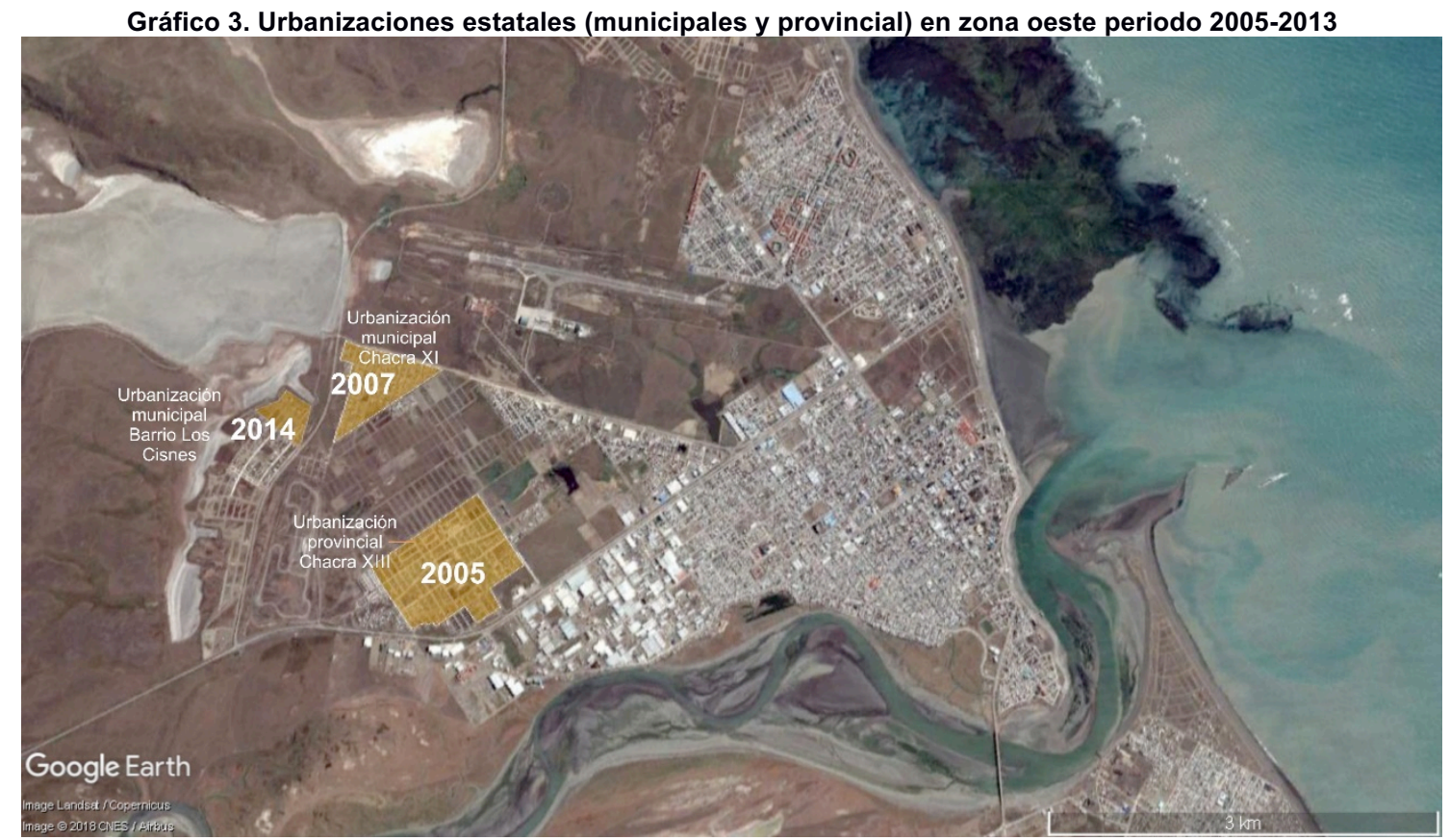

Fuente: elaboración propia en base a imagen satelital procesada con Google Earth, 2013 
Por otro lado, como adelantamos en apartados anteriores, en la zona sur de la ciudad a finales de 2005 inicia un proceso de continua formación de barrios autoproducidos. Se trató del proceso de autoproducción del hábitat más relevante de los últimos veinte años en la localidad (gráfico 6).

Los tejidos residenciales producidos por el estado y por la autoproducción representaban ya en 2010 al 53\% del total de tejidos de las áreas de expansión. En particular el ATLAS ID identificó que, en el caso de los tejidos residenciales de vivienda social, estos alcanzaron al $26 \%$ mientras que para el caso de asentamientos éstos fueron del $27 \%$. Desde nuestra perspectiva, ello da cuenta de la preponderancia de la lógica de producción de ciudad pública y "de necesidad", por sobre la producción urbana producto de la lógica de la ganancia.

El caso riograndense en este sentido y de acuerdo al informe citado, adquiere relevancia en cuanto se la compara con el conjunto de las 21 ciudades estudiadas: para el total de la muestra, la incidencia de la vivienda social es del $16 \%$ mientras que en el caso de Río Grande, lo supera por lo menos en 10 puntos porcentuales $(26 \%)$. Para el caso de tejidos del tipo "villas y asentamientos" en las áreas de expansión urbana, en el caso riograndense como notamos alcanza a un $27 \%$ mientras que en el conjunto de aglomerados urbanos es del $6 \%$ como se observa en el gráfico 4 . El estudio sostiene que para el conjunto de ciudades, la mayor participación de tejidos residenciales es de loteos formales y grandes parcelas residenciales, por ende se trataría de tejidos destinados a usos de sectores de ingresos medios a altos: loteos formales y grandes parcelas residenciales.

\section{Gráfico 4. Gráfico tejidos residenciales en áreas de expansión urbana según INDEC 1991, 2001 y 2010}

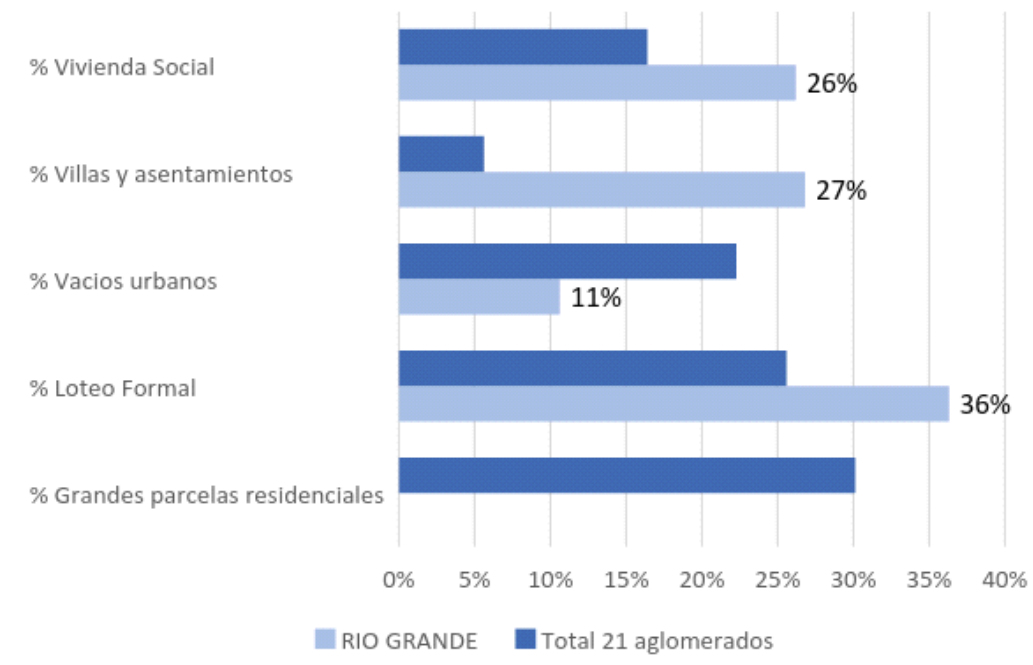

Fuente: elaboración propia en base a "Tejidos residenciales en áreas de expansión urbana" - Atlas-ID Sistema de Indicadores Territoriales, construido en base a datos INDEC 1991, 2001 y 2010

La tendencia del crecimiento urbano del caso riograndense se caracterizó por una baja densidad. El ATLAS ID a partir del indicador "densidades de población" del periodo 1991-2010, infiere patrones de urbanización respecto del crecimiento poblacional y la expansión urbana. En este sentido, Rio Grande también se destaca por haber sufrido en el periodo una merma en su densidad (cantidad de habitantes por km2) y un incremento de la población y superficie urbana tal como se observa en el gráfico 5 . En efecto, tanto en términos de población como de superficie urbanizada, la localidad supera al promedio de la totalidad de casos y lo hace en mayor medida (cerca del doble) en cuanto al crecimiento de la población: $74 \%$ frente al $39 \%$ respectivamente. 


\begin{tabular}{ccc} 
& $\begin{array}{l}\text { Variaciones relativas de } \\
\text { superficies, población y } \\
\text { densidad del período } \\
1991-2010\end{array}$ \\
\hline & $\begin{array}{l}\text { Variación promedio } \\
21 \text { conglomerados }\end{array}$ & \\
\hline Población & $39 \%$ & $74 \%$ \\
Superficie & $116 \%$ & $132 \%$ \\
Densidad & $-32 \%$ & $-25 \%$
\end{tabular}

Fuente: elaboración propia en base a "variación de densidades entre 1991 y 2010 " y "variaciones de promedio de superficie, población y densidad (21 casos)" - Atlas-ID Sistema de Indicadores Territoriales, construido en base a datos INDEC 1991, 2001 y 2010

Esta tendencia continua para el periodo 2010-2016. Según el estudio de Martínez (2017:61) "la mancha urbana [de Río Grande] pasó de 14,5 a $25,25 \mathrm{~km} 2$, mostrando un incremento porcentual del $85 \%$ de la superficie urbanizada, para ese mismo periodo, la densidad disminuye de 5.057, 23 habitantes por $\mathrm{km} 2$ a $3.770,15$ habitantes por km2". El autor sostiene que la expansión de la mancha urbana se da de manera más marcada en la zona sur de la ciudad: en la Margen Sur. Al año 2013, el municipio de la ciudad calculó la superficie correspondiente a los nuevos barrios autoproducidos por las familias ocupantes: 265,43has, equivalente a 2618 parcelas (Municipio de Rio Grande, 2014).

El descenso de la densidad en las ciudades llama la atención sobre la sustentabilidad urbana, en tanto significa un incremento de los costos vinculados a la provisión de servicios urbanos (recolección de residuos, infraestructuras básicas y equipamientos comunitarios (educación, salud, seguridad, etc.), transporte público, etc.); la pérdida de suelo productivo en áreas periurbanas, la necesidad de contar con mayor cantidad de electricidad dada la lejanía de las zonas de expansión entre otros. Si bien la producción de suelo y vivienda por la lógica privada fue relevante en las áreas de expansión, resulta importante anotar que, por ejemplo, para el caso del suelo urbano, en el periodo 2004-2013 existió un empeoramiento de las posibilidades de acceso en el mercado formal y privado. EI ATLAS ID (2015) identificó al respecto, que las familias necesitaron más ingresos entre un año y otro para acceder a un lote tipo $(300 \mathrm{~m} 2)$ en las distintas áreas clasificadas de la ciudad (centrales, barrios consolidados, áreas de expansión y áreas de renovación). En cuanto a la evolución de los precios corrientes del suelo $(\$ / \mathrm{m} 2)$ para el caso de municipio de Río Grande, el estudio identificó un crecimiento de más del 2000\% en el periodo 2004-2013, tanto en áreas de expansión: $2047 \%$, como en barrios consolidados: $2233 \%$.

Si bien los ingresos de las familias mejoraron en este periodo: 9 veces más entre 2004 y 2013 , el precio del suelo aumentó 23 veces (Atlas ID, 2015), por lo que el acceso nunca mejoró, sino por el contrario, empeoró para todas las familias y lo hizo de peor manera para aquellas con menores ingresos. Estas últimas, para acceder a una parcela tipo (300 metros cuadrados) en las áreas de expansión, en 2013 necesitaron 15 ingresos más que en 2004. (Atlas ID, 2015:61). Es necesario avanzar en el estudio de la actualización de estos resultados.

\subsection{CRECIMIENTO URBANO EN LAS DISTINTAS ZONAS DE LA CIUDAD}

Entendemos que las tendencias anotadas tuvieron un rol importante en la configuración de la ciudad producida; consideramos en este sentido que resulta necesario vincularlas con las características particulares que asumieron las distintas zonas de las áreas de expansión para identificar si es posible reconocer preponderancias de tipos de tejidos y a la luz de esos resultados, analizar la participación del estado local en las áreas de expansión en su conjunto.

\section{SUR}

La ciudad creció hacia el sur prioritariamente a partir de la autoproducción. Ello se dio en el marco del proceso de surgimiento de tomas de tierra o asentamientos, de características semejantes a las ya señaladas por Varela y Cravino (2008:59-60) para el caso de Buenos Aires, entre otras: tienen trazados que tienden a ser regulares y planificados, a la vez que son decididos y organizados colectivamente con una estrategia previa (a la toma) que a veces implica la participación o apoyo de otras organizaciones. Se 
ubican en tierra vacante (publica y/o privada), implementando una estrategia de mediación con el Estado luego de la ocupación para lograr la legitimación; las viviendas son transformadas con el tiempo y los lotes (unidad lote-vivienda) tienden a densificarse, los espacios privados y públicos son diferenciados, quedando estos últimos a resguardo para ser destinados a plazas u equipamientos comunitarios.

Muchos de los nuevos barrios de la Margen Sur del Rio Grande se asentaron sobre áreas inundables, donde se produce el desborde de los pozos ciegos utilizados para el desagote de efluentes domiciliarios. En algunos casos las propias arterias anegadas por el agua y barro impedían el ingreso de las ambulancias, camiones de bomberos o el propio transporte de pasajeros. El sistema de calefacción precario devino en muchas situaciones en ígneos con consecuencias gravísimas sobre la vida de las familias afectadas. En definitiva, todo un abanico de condicionantes que atentan contra la calidad de vida de los habitantes.

Esta realidad desde sus inicios, en 2005 presentó un gran desafío para los Estados, sobre todo respecto de la regularización para una posterior urbanización en los casos en los que la tierra era privada. A diferencia de Ushuaia, donde se implementó una política de desalojos por parte del municipio (Martinez y Finck, 2017), en Río Grande a la vez que se omitió la práctica de desalojos violentos, se promovieron leyes de expropiación gestionadas desde el gobierno provincial (en el año 2010). Esto último acarreó discusiones públicas en torno de la valorización apropiada por los titulares originales (en concepto de pago por lo tasado para ejecutar la expropiación de acuerdo a la normativa argentina). También se pudo observar entre otras cuestiones, un cuestionamiento de la legitimidad del derecho de las familias habitantes de los asentamientos a la titularidad de la tierra.

Otra serie de acciones estuvieron en manos del gobierno local. Al momento de producidas las ocupaciones de 2005, el suelo en esta zona de la ciudad, desde el punto de vista del uso, se correspondía con una zona suburbana. Como adelantamos, en 2011 se realizó una readecuación de la zonificación planteada en 2005 y, para el caso de la localización de asentamientos se la clasificó como "Zona Especial de Interés Social" (ZEIS) que son aquellas "ocupadas por o destinadas a loteo y/o vivienda social en los que existe el interés público en ordenar y mejorar la ocupación, en urbanizar y producir procesos de regularización dominial y que, por lo tanto, están sujetas a criterios especiales de parcelamiento, ocupación y uso del suelo" (Valdeiglesias, 2013). Esta acción posibilitó el inicio de obras de mejoramiento por parte de estado local a partir de la provisión de infraestructura básica (agua, cloacas, pluviales) tanto desde el gobierno provincial como del municipal y a partir de financiamiento federal en la mayoría de los casos.

Por otro lado, en la zona sur se llevaron adelante una serie de urbanizaciones privadas que implicaron en algunos casos discusiones publicas en torno a la colisión de usos por la creación de una reserva natural en Punta Popper en 2012, en la desembocadura del Rio Grande (Ordenanza Municipal №3042/2012). En el periodo se desarrollaron al menos dos urbanizaciones por parte del estado provincial a través de Programas Federales de Vivienda, aunque las mismas en el conjunto de la producción de suelo y vivienda, tienen un peso relativo minoritario. Más allá de estas acciones, se destaca en esta zona la producción de ciudad por la lógica de la necesidad. 


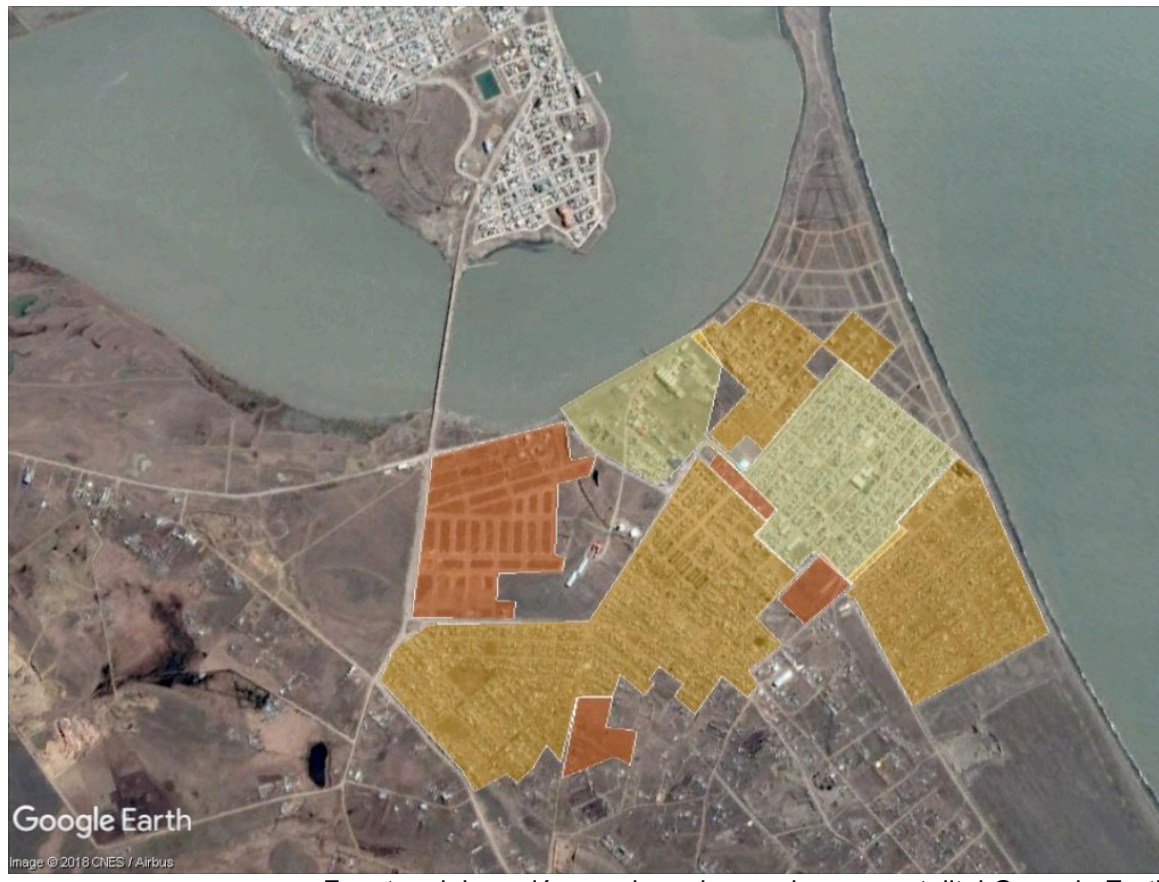

Proceso de expansión urbana zona sur 2005-2016

año 2005

aก̃o 2013

año 2016

Fuente: elaboración propia en base a imagen satelital Geoogle Earth

\section{OESTE}

Durante el periodo de interés, la intervención del Estado en materia de producción de vivienda y suelo urbano no fue ni homogénea ni necesariamente armoniosa entre sus distintos niveles. El estado provincial en 2005 inicia las obras de 1017 viviendas en un polígono que no tenía continuidad con la trama urbana como ya mencionamos. El Instituto Provincial de la Vivienda (IPV), que es el organismo descentralizado del gobierno provincial a través del cual se ejecutan los programas federales de vivienda y otras políticas de vivienda desde ese nivel de gobierno, adquirió la tierra en el año 2001 a partir de un canje con privados por otras tierras en áreas consolidadas de la ciudad. A fines de 2008, parte de las viviendas fueron entregadas en guarda sin servicios básicos tales como las cloacas. Estas obras complementarias debieron ser financiadas por el municipio. Dos años más tarde, en 2010, se instaló la red cloacal colectora zona norte, una obra de gran envergadura que impactó de manera directa sobre toda la zona norte que se encontraba en vías de urbanización.

Este ejemplo da cuenta no solo de la complejidad implícita en materia de articulación interjurisdiccional, sino también los modos de crecimiento urbano, que pueden a la vez generar paradójicamente efectos negativos en la calidad de vida de la población destinataria de las viviendas de interés social. A priori podríamos sostener que la acción del estado provincial precipitó el desarrollo urbano de la zona oeste de la ciudad que hasta ese entonces no se había urbanizado. En efecto, luego de la urbanización de Chacra XIII (Barrio Malvinas Argentinas), que significó la producción de más de dos mil viviendas (lote-vivienda y vivienda en conjunto habitacional), se realizó un nuevo canje de tierras pero esta vez fue a partir del accionar del estado local en el año 2004. Esto posibilitó el desarrollo un loteo público que se concretó entre los años 2007 y 2009. A ello se sumó el desarrollo de otros dos barrios de vivienda de interés social en la misma gran zona.

El crecimiento urbano residencial formal que se localizó entonces en el oeste de la ciudad no siguió un patrón de completamiento de la mancha urbana, sino que fue desarrollándose por "mojones" o fracciones, principalmente a partir de intervenciones directas por parte del Estado, a nivel provincial y municipal. Los fraccionamientos privados que se produjeron en las áreas intersticiales fueron a posteriori de las urbanizaciones estatales por lo que esos propietarios pudieron captar las valorizaciones que el estado realizó sin generar por ello alguna contrapartida. 
Gráfico 7. Acciones de producción urbana bajo la lógica publica, periodo 2005-2015, zona oeste de la ciudad

\begin{tabular}{|c|l|c|c|}
\hline Urbanización & $\begin{array}{c}\text { Nivel de estado (carácter } \\
\text { de la intervención) }\end{array}$ & $\begin{array}{c}\text { Año de inicio } \\
\text { - finalización }\end{array}$ & Unidades habitacionales \\
\hline $\begin{array}{c}\text { Chacra XIII (Barrio } \\
\text { Malvinas } \\
\text { Argentinas) }\end{array}$ & $\begin{array}{l}\text { Provincial - IPV } \\
\text { (Interjurisdiccional: Nación - } \\
\text { Provincia) }\end{array}$ & $2005-2017$ & $\begin{array}{c}248 \text { lotes con servicios (programa para } \\
\text { radicación de jóvenes) }\end{array}$ \\
\hline Chacra XI & Municipal & $2007-2011$ & $\begin{array}{c}690 \text { lotes con servicios } \\
20 \text { viviendas sociales }\end{array}$ \\
\hline Barrio Los Cisnes & $\begin{array}{l}\text { Municipal (Interjurisdiccional: } \\
\text { estado nacional, provincial y } \\
\text { municipal) }\end{array}$ & $2011-2015$ & $\begin{array}{c}136 \text { lotes con servicios (garantizados de } \\
\text { manera progresiva) }\end{array}$ \\
\hline $\begin{array}{c}\text { Barrio del } \\
\text { Bicentenario }\end{array}$ & $\begin{array}{l}\text { Municipal (interjurisdiccional: } \\
\text { estado nacional, provincial y } \\
\text { municipal) }\end{array}$ & $2014-2016$ & 150 viviendas sociales terminada \\
\hline
\end{tabular}

Fuente: elaboración propia en base a informes técnicos y documentación cuantitativa Instituto Provincial de la Vivienda y municipio de Rio Grande

La mixtura de acciones (conjuntos habitacionales multifamiliares, loteos, vivienda unifamiliar (es decir en lote individual) como se observa en el gráfico 7 posee el rasgo común de haber tenido, en general, alguna dificultad en la provisión de servicios de red esenciales para estas frías latitudes, lo que incluye a su vez el gas natural por red. Por otro lado, en todos los casos y hasta 2011 inclusive, la adquisición de suelo urbano del estado fue por medio de canjes de predios en macizo con privados. Desde la creación del Banco de Tierras Municipal, en el año 1997, hasta el 2015 inclusive, nunca se realizó una compra de tierras para urbanizar (Finck, Martínez et al, 2017).

En definitiva, entre 2005 y 2015 en la zona oeste se destaca la participación de los tejidos residenciales de vivienda de interés social, aunque estas viviendas adquirieron características diferentes, como explicamos, en cuanto a calidad, metros cuadrados o modalidad de producción -empresa privada o cooperativa-.

\section{NORTE}

El Plan de Desarrollo Territorial (Ordenanza 2863/2011) elaborado por el municipio a partir de financiamiento internacional, estableció como áreas prioritarias de urbanización las ubicadas en la zona norte y oeste de la ciudad. En vinculación con ello, las grandes obras de infraestructura entre 2005 y 2011 se proyectaron prioritariamente con esa orientación. En el norte de la ciudad se localizaron preponderantemente desarrollos inmobiliarios privados que se localizaron de forma lindante a los tejidos ya consolidados décadas anteriores -principalmente de vivienda social en conjuntos habitacionales-. En esta zona, se autorizaron desarrollos inmobiliarios donde los lotes son de grandes dimensiones y en muchos casos, dada la pendiente sobre la que se ubican estas urbanizaciones, con acceso al paisaje de la costa del mar argentino. Uno de los casos más paradigmáticos de esta zona lo constituye el desarrollo denominado Altos de la Estancia, un barrio que según los discursos de los responsables se propone ser "el más moderno de la ciudad" y donde precios de los terrenos y dimensiones, fue mayor en comparación con lotes y precios en áreas consolidadas, lo que refuerza la orientación de los destinatarios de los mismos.

Asimismo, se destaca de este sector de la ciudad la localización de intervenciones del municipio por medio de asociación público-privada. Ello fue posible a partir de 2014 como adelantamos, cuando se dispuso crear por ordenanza la Zona Residencial de Interés Público Privado (ZRIPP). El suelo generado bajo esta modalidad a partir del formato de fideicomiso estuvo destinado a familias inscriptas en el padrón de demanda de tierras municipal y que contasen con capacidad de ahorro para afrontar el costo del financiamiento de los lotes. De esta manera en el año 2015 el Fideicomiso San Martin Norte, dispuso la venta de 1.800 lotes; el proyecto alcanzó a 68has dentro de la urbanización Misión Grande aunque las dimensiones de los terrenos en algunos casos implicó dimensiones menores a las de los terrenos promedio en la ciudad: las dimensiones fueron iban desde los 180m2 a los 300m2 (Web BC Ushuaia, 2018).

La autorización de esta urbanización implicó la aplicación del instrumento de contribución por mejoras (Ordenanza N ${ }^{\circ}$ 2933/2011). Para este caso (subdivisión), se establece que el tributo a pagar se corresponda con el $20 \%$ de los lotes del nuevo fraccionamiento. Fue a partir de este instrumento que el municipio accedió a un porcentaje de los lotes en la zona norte donde prevé, según anuncios oficiales realizados en febrero de 2018 (Diario El Sureño, 16/2/2018), desarrollar proyectos por más de 800 viviendas bajo la 
modalidad público-privado, por lo que se presume que las familias destinatarias de tal modalidad deberán contar, al igual que la experiencia mencionada, con cierto nivel de ingresos o capacidad de pago para acceder a tales viviendas.

Durante este periodo también se desarrollaron barrios destinados al sector de trabajadores estatales a partir de operaciones entre diferentes niveles jurisdiccionales. Así, por ejemplo, en la zona norte también se desarrolla una urbanización destinada a empleados públicos agremiados a la "Asociación de Trabajadores Estatales" (ATE). El predio fue cedido por el municipio a ATE, y la articulación entre el Banco de Tierra del Fuego y el Instituto Provincial de la Vivienda y el propio municipio, posibilitó la constitución de un Fideicomiso para la construcción de 120 viviendas. En este caso también, se trataría de un mecanismo de acceso a sectores medios, que cuentan con trabajo asalariado y condiciones de sostenibilidad del empleo. Esta última acción está indicando un cambio en la división socio-espacial de la ciudad de Rio Grande, incorporando a modalidades de viviendas de producción estatal en la zona norte. No obstante, no responde a los modelos clásicos de oferta de construcción de viviendas, individual, sino a modalidades asociativas a la vez que se trata en definitiva de una operatoria público-privada. Desde nuestra perspectiva, esto refuerza, aunque con particularidades, los procesos de diferenciación en la división social del espacio mediante el cual los sectores de ingresos medios o medios altos se localizan en la zona norte.

\section{PRIMERAS REFLEXIONES, NUEVAS APERTURAS}

En el periodo que estudiamos (2005-2015) el crecimiento urbano de Rio Grande se caracterizó por la expansión con baja densidad. A su vez, la población también creció particularmente por migración interna y esto fue motivado por decisiones de política pública de nivel nacional, es decir, de acuerdo a condiciones exógenas. Como ciudad receptora de población, además de un incipiente crecimiento vegetativos, no tuvo la capacidad de dar lugar a un acceso amplio al suelo urbano y a la vivienda. En particular dado el contexto de un mercado inmobiliario cada vez más restrictivo y el desenvolvimiento de una política de producción de vivienda de interés social centrada en el nivel provincial y nacional que no alcanzaba la escala suficiente.

Por otra parte, notamos que la participación del estado local adquirió en el período de estudio un rol central aunque con variaciones. Fue alcanzando una participación mayor en el proceso de producción urbana caracterizada por un progresivo robustecimiento y autonomización jurídico a la vez que, en particular desde 2011, diversificó los mecanismos de acceso al suelo urbano y la vivienda. Aun así, poniendo en vinculación el rol estatal, con el proceso más general de expansión urbana y observando en el plano de la ciudad construida, la participación de los distintos tejidos residenciales preponderantes, es posible observar una serie de tendencias que demostrarían los rasgos generales que caracterizaron la intervención del estado. A su vez, podemos reconocer dónde se localizó preponderantemente la autoproducción de vivienda y la ciudad producida a partir de la lógica privada.

Sostenemos aquí que las estrategias implementadas por el estado municipal, y con intervención del estado provincial, han sido diferenciadas en lo que respecta al gran área del norte y oeste de la ciudad: mientras que en la zona norte se concentraron nuevas urbanizaciones promovidas por desarrolladores inmobiliarios privados o bien a través de estrategias público-privadas (destinadas a sectores medios), en el caso de la zona oeste de la ciudad se radicaron durante este periodo, la mayor parte de las estrategias de producción de tejidos residencias de vivienda de interés social. En la zona sur por su parte, fueron los tejidos residencias de vivienda autoconstruida en áreas inundables o degradadas ambientalmente (cercanía a antiguos basurales por ejemplo) los que adquirieron mayor relevancia. Aquí, el estado en su nivel local y provincial centraron su intervención en acciones de mejoramiento y urbanización.

Estas características evidencian un desigual acceso a la ciudad y con ello a las externalidades urbanas que en algunos casos fue positiva y en otros negativa, supuso en definitiva la ocupación desigual de un lugar en la ciudad. La localización de las nuevas urbanizaciones no fue un factor ponderado al momento de definir donde se ubicarían las viviendas de interés social. Por ejemplo, a nivel municipal, en el caso paradigmático del Barrio Los Cisnes, éste se ubicó por fuera de ruta de circunvalación №3 que operaba de límite para el completamiento urbano. Recién en 2018 los colectivos pudieron ingresar al barrio y de este modo garantizar conectividad desde el punto de vista de la la movilidad.

En la división social del espacio, el estado destinó la zona norte al mercado de suelo de clase media y media alta y es allí donde además localizó un barrio de vivienda estatal pero destinado a sectores de 
ingresos medios compuesto por empleados públicos del estado. La participación de un banco para el otorgamiento de créditos a las familias destinatarias sugiere una modalidad de articulación público-privada. Existieron otras acciones de articulación con colectivos gremiales pero se redujo al traslado de dominio de tierras fiscales por parte del estado local las cuales se concentraron en la zona oeste de la ciudad principalmente (Martinez, Finck et al, 2017).

Resulta importante analizar en profundidad si estas localizaciones diferenciadas se corresponden en efecto con procesos de diferenciación urbana que involucren un distanciamiento de sectores sociales en el espacio urbano de acuerdo a su nivel de ingreso. Por otro lado, el impacto sobre la organización cotidiana de las familias respecto de las distancias y tiempos de traslado entre los barrios creados en las áreas de expansión y el centro de la ciudad, es un tema de análisis para indagar, en particular respecto de los efectos que la expansión urbana tuvo, no solo en términos de sustentabilidad de los servicios públicos, sino respecto de las familias allí residentes. Por último, entendiendo que, en muchos de los casos, la producción de vivienda o suelo urbano en las áreas de expansión no significó necesariamente para las y los usuarios el acceso a la ciudad y con ello a los bienes socialmente valorados, resultaría pertinente profundizar en los repertorios de lucha de los habitantes y la respuesta en términos de procesamiento de la demanda que realizó el propio estado. 


\section{BIBLIOGRAFÍA}

Alonso Marchante, J. L. (2014) Menéndez. Rey de la Patagonia. Losada. Argentina.

Arqueros Mejica y Canetastro, M. L. (2011). Arqueros Mejica, M. S. y Canetastro, M. L. (2011). Intervenciones del estado en la regularización de villas y asentamientos: alcances, límites y contradicciones en Di Virgilio, M. M., Herzer, H., Merlisnky, M. G., \& Rodríguez, M. C. (2011). La cuestión urbana interrogada. Transformaciones urbanas, ambientales y políticas públicas en Argentina. PP. 39-74

Bachiller (2015) Una introducción general sobre las dificultades de acceso al suelo urbano y la toma de tierras en la Patagonia central. En Toma de tierras de acceso al suelo urbano en la Patagonia central, Santiago Bachiller editor. Universidad Nacional de la Patagonia Austral. Miño y Davila Editores. Buenos Aires, Argentina.

Bandieri S. (2000) Ampliando las fronteras: la ocupación de la Patagonia en Nueva historia Argentina: El Progreso, la modernización y sus límites (1880-1916). Ed. Sudamericana, Buenos Aires.

Basualdo, J. L. (2016). Qué es un instrumento. Documento del autor empleado como recurso en el curso "Revisando los Fundamentos de la planificación para la gestión del suelo". Lincoln Institute of Land Policy.

Bellet Sanfeliu, C y Llop Torné, J. M. (2004) Miradas a otros espacios urbanos: las ciudades intermedias. Catedra UNESCO UdL - Ciudades Intermedias - Ubranización y desarrollo.

Bourdieu, P (2013). La miseria del mundo. Fondo de cultura económica 2013.

Bou, (1995) Bou, M.; Repetto, E.; Susic de Bonifetti, E.; Sutherland, S.; Allen, A. y Stanic, D. (1995): A hacha, cuña y golpe - Recuerdos de pobladores de Río Grande. Ed. de los autores. Argentina

Erbiti (2007) Transformaciones del sistema urbano argentino a fines del Siglo XX: Desafíos para la gestión del territorio. IV Seminario Ordenamiento Territorial. Ordenamiento territorial y Problemáticas urbanas. UNCUYO. Mendoza.

Finck, N. (2016) Políticas municipales de producción de suelo y vivienda : el caso del municipio de Río Grande (Pvcia. de Tierra del Fuego, Antártida e Islas del Atlántico Sur (AIAS)) (En línea). Trabajo presentado en IX Jornadas de Sociología de la UNLP, 5 al 7 de diciembre de 2016, Ensenada, Argentina.

Finck, N.; Lobato, S.; López, J.; Martínez, A.; Moreno Russo, F. (2016) Las ciudades fueguinas en perspectiva comparada : Un análisis de las políticas de producción de suelo y vivienda en Ushuaia y Río Grande, durante la última década (2005-2015) (En línea). Trabajo presentado en IX Jornadas de Sociología de la UNLP, 5 al 7 de diciembre de 2016, Ensenada, Argentina.

Gutierrez, D. (2001) Temprano Río Grande. Ed. Osvaldo Santarone, Industria Gráfica Eleven Press s.r.I. Argentina.

Harvey, D. (2016) Urbanismo y desigualdad social. 7ma edición. Siglo XXI España. España

Hermida, M.; Malizia, M.; van Aert, P. (2013) "Migración en Tierra del Fuego (o la historia de una ida y una vuelta)" en Sociedad Fueguina Nro 2, Año 1, Instituto de Cultura, Sociedad y Estado, Universidad Nacional de Tierra del Fuego, Ushuaia disponible en http://200.61.137.30/pagina_2012/wpcontent/uploads/2013/08/SociedadFueguina_Nro24.pdf consultado el 21 de febrero de 2014.

Imaz, J. L. (1972) Los hombres del confin del mundo. Tierra del Fuego. Eudeba Editores: Argentina.

Lefebvre, H., \& Lorea, I. M. (2013). La producción del espacio. Capitán Swing. Madrid, España.

Lorenzo, A. (2012) Pensando el espacio fueguino en clave capitalista. Vinculaciones entre actores privados y sociedades indígenas en la Tierra del Fuego, 1880-1930. III Congreso Latinoamericano de Historia Económica y XXIII Jornadas de Historia Económica. Bariloche, Argentina.

Maldonado Copello, M.M. (2009). ¿Es posible anticiparse a la urbanización informal? Reflexiones a partir de la Operación Urbanística Nuevo Usme, Bogotá y del Macroproyecto Ciudadela Gonzalo Vallejo Restrepo, Pereira (Colombia). Regularización de asentamientos informales en América Latina. Cambridge: Lincoln Institute of Land Policy. 
Martinez, A., Finck, N., Lobato, S. y Moreno Russo, M. F. (2017) El suelo público para qué y para quiénes: distribución de tierras fiscales en Tierra del Fuego (2005-2015). XII Jornada de Sociología. 22 al 25 de agosto. Universidad Nacional de Buenos Aires. Mesa 75: Territorios, políticas habitacionales y centralidades urbana. Buenos Aires, Argentina.

Maveroff, A. (1979) Rio Grande: ciudad treinta años antes de su fundación formal. Municipalidad de Río Grande, Territorio Nacional de la Tierra del Fuego, Antártida e Islas del Atlántico Sur.

Ozslak, O. y O’Donell, G. (2011). Estado y políticas estatales en América Latina: Hacia una estrategia de investigación. En Proyecto de Modernización del Estado - Jefatura de Gabinete de Ministros de la Nación, Lecturas sobre el Estado y las políticas públicas: Retomando el debate de ayer para fortalecer el actual (pp. 555-584). Buenos Aires: Jefatura de Gabinete de Ministros de la Nación.

Petrov-Schapira, M-F y Velut, S. (2016) El sistema urbano y la metropolización en Kessler Gabriel (2016) La sociedad argentina hoy: radiografía de una nueva estructura. 1ra ed. Ed. Siglo Veintiuno Buenos Aires: Buenos Aires.

Pírez, P. (1995) "Actores sociales y gestión de la ciudad" en Ciudades, Red Nacional de Investigación Urbana, Año 7, No. 28, octubre-diciembre 1995, México.

Reyes, S. (2003) Estudio Preliminar en Popper (2003) Atlanta. Buenos Aires: Eudeba.

Rodríguez, M. C., Di Virgilio, M. M., Procupez, V., Vio, M., Ostuni, F., Mendoza, M., Morales, B. (2007) Política del hábitat, desigualdad, y segregación socio-espacial en el Área metropolitana de Buenos Aires. AEU-IIGG/FSOC-UBA Área de Estudios Urbanos Instituto de Investigaciones Gino Germani Grupo Argentina de Producción Social del Hábitat hic-al FVC - MOI-SEDECA. Buenos Aires, Argentina.

Rodríguez, M. C. (2010). Las políticas habitacionales argentinas post 2001: Entre la gestión de la "emergencia" y la emergencia de la producción autogestionaria. Observatorio Social sobre Empresas Recuperadas y Autogestionadas. Buenos Aires, Argentina.

Soja, E. (2016) La ciudad y la justicia espacial. En Bret, B., Gervais-Lambony, P., Hancock, C y Landy, F. (comp) (2016) Justicia e injusticias espaciales. UNR Editora: Rosario, Argentina.

Vapñarsky, C. y Gorojovsky, N. (1990): El crecimiento urbano en la Argentina. Grupo Editor Latinoamericano (GEL). Buenos Aires.

Varela, O. y Cravino M. C. (2008) Mil nombres para mil barrios. Los asentamientos y villas como categorías de análisis e intervención. En Los mil barrios. Los mil barrios (in)formales: aportes para la construcción de un observatorio del hábitat popular del área metropolitana de Buenos Aires. Cravino M. C. coord. Universidad Nacional de General Sarmiento. Buenos Aires, Argentina.

\section{Revistas}

Abramo, P. (2008) El mercado del suelo informal en favelas y la movilidad residencial de los pobres en las grandes metrópolis: un objeto de estudio para América Latina. Territorios, núm. 18-19, enero-diciembre, 2008, pp. 55-73.

Bandieri, S. (2006) Del discurso poblador a la praxis latifundista: la distribución de la tierra pública en la Patagonia. Mundo Agrario, vol. 6, $\mathrm{n}^{\circ}$ 11, segundo semestre de 2005. Universidad Nacional de La Plata.

Cravino, M. C., Fernandez Wagner, R. (2006) Teoria y política sobre asentamientos informales. Cuestionario a Raúl Fernandez Wagner y Maria Cristina Cravino, en vísperas del Seminario en la UNGS. Revista digital Café de las Ciudades. Año 5. Número 49. Noviembre 2006. Recuperado de http://www.cafedelasciudades.com.ar/politica_49_2.htm

Manzano, F. y Velazquez, G. (2015) La evolución de las ciudades intermedias en la Argentina. Revista GEO UERJ. N27, p. 258-282. Rio de Janeiro, Brasil.

Martínez, A.; Finck, N. (2017) La política de desalojos en el fin del mundo: el caso del Municipio de Ushuaia, Argentina, en el período 2007-2015. Revista Ciudades, Estados y Política, [S.I.], v. 4, n. 1, p. 59-78, ene. 2017. Disponible en: https://revistas.unal.edu.co/index.php/revcep/article/view/57312. Colombia.

Oszlak, O. (1983) Los sectores populares y el derecho al espacio urbano. Revista Punto de vista. Buenos Aires, Argentina. 
Perez, V., Martinez, A. (2014) Habitar nuestro suelo: Una aproximación a la realidad habitacional de Tierra del Fuego. Sociedad Fueguina. Numero 3. Año 2. Agosto. Documento del Instituto de Cultura Sociedad y Estado. Universidad Nacional de Tierra del Fuego, Antártida e Islas del Atlántico Sur. Tierra del Fuego, Argentina.

Reese, E. (2011) Instrumentos de gestión urbana, fortalecimiento del rol del municipio y desarrollo con equidad. Revista Carajillo de la Ciudad. AÑO 3 - Octubre 2011. Disponible en http://cafedelasciudades.com.ar/carajillo/10_art4.htm

Smolka, M. (2003). Informalidad, pobreza urbana y precios de la tierra. Land Lines, 15(1), 135.

Vapñarsky, C. (1995) Primacía y macrocefalia en la Argentina: la transformación del sistema de asentamiento humano desde 1950. Desarrollo Económico. Vol. 35, No. 138 (Jul. - Sep., 1995), pp. 227-254. Argentina.

\section{Leyes, Ordenanzas y Decretos}

\section{Nacionales}

Territorios nacionales. Ley Nacional №1532 (1884).

Nuevo régimen especial fiscal y aduanero. Ley Nacional №19640 (1972).

\section{Territoriales}

Ley Territorial de Municipalidades. Ley Territorial Tierra del Fuego AIAS N²36 (1984)

\section{Provinciales}

Constitución Provincial Tierra del Fuego Antártida e Islas del Atlántico Sur (1991)

\section{Municipales}

Carta Orgánica Municipal Municipio de Rio Grande, Pcia. de Tierra del Fuego, Antártida e Islas del Atlántico Sur.

Código de Planeamiento. Ordenanza Municipal Nro. 2863 (2011)

Código tributario. Ordenanza Municipal Nro.2933 (2011)

Establece RNU (Reserva Natural Urbana), zona Punta Popper. Ordenanza Municipal Nro. 3042 (2012)

Crea Zona Residencial de Interés Público Privado. Ordenanza Municipal Nro. 3387 (2014).

\section{Fuentes electrónicas}

BC USHUAIA (2018). Fideicomiso San Martín Norte. Disponible en http://www.bcushuaia.com.ar/es/index.php/desarrollos/emprendimientos/fideicomiso-san-martin-norte

Diario el Sureño (2018). "Melella anuncio la construcción de 800 viviendas y nuevos servicios de Quimioterapia y Cardiología" Consulta: 16/2/2018 Disponible en http://www.surenio.com.ar/2018/02/melellaanuncio-la-construccion-800-viviendas-nuevos-servicios-quimioterapia-cardiologia

Gobierno de la Provincia de Tierra del Fuego. "La gobernadora Bertone puso en marcha el fideicomiso para la construcción de 120 viviendas en Río Grande". Consulta: 17/02/2018. Disponible en https://www4.tierradelfuego.gov.ar/la-gobernadora-bertone-puso-en-marcha-el-fideicomiso-para-laconstruccion-de-120-viviendas-en-rio-grande/

Actualidadtdf.com.ar (2018) "Bertone puso en marcha el fideicomiso para la construcción de 120 viviendas para ATE en Río Grande". Consulta: 15/2/2018. Disponible en http://actualidadtdf.com.ar/bertone-puso-enmarcha-el-fideicomiso-para-la-construccion-de-120-viviendas-para-ate-en-rio-grande/

SUR54 (2009) Río Grande: Acuerdo de Gobierno, Municipio y adjudicatarios de Chacra XIII por obras para servicios". Consulta: 17/2/2018. Disponible en: http://www.sur54.com/rio-grande-acuerdo-de-gobiernomunicipio-y-adjudicatarios-de-chacra-xiii-por-obras-para-servicios 
LALICUADORATDF (2009) Obras Públicas realiza tareas de desagote en el sistema cloacal de Chacra XIII. Consulta: 17/2/2018. Disponible en: http://www.lalicuadoratdf.com.ar/2009/05/obras-publicas-realiza-tareasde-desagote-en-el-sistema-cloacal-de-chacra-xiii/

\section{Documentos e Informes del sector público}

Martínez, S. (2017) Modelo de proyección de necesidades basado en dinámicas demográficas, para la gestión integral del hábitat. Provincia de tierra del fuego, Antártida e Islas del Atlántico Sur. Informe final. Consultor 3 sistemas de Información geográfica. Anexo cartográfico. Subsecretaria de Planificación Territorial de la Inversión Pública. Programa de fortalecimiento Institucional Préstamo CAF7353. Disponible en https://www.mininterior.gov.ar/planificacion/pdf/planes-prov/tierra-del-fuego/Tierra-Fuego-Antartida-IslasAtlanticoSur.pdf.

Ministerio de Planificación Federal, Inversión Pública y Servicios (2015) ATLAS ID. Indicadores de Desarrollo Territorial de la República Argentina. Buenos Aires. Argentina.

Ministerio de Planificación Federal e Inversión Pública (2011). Argentina Urbana. Buenos Aires.

Municipio de Rio Grande (2014) Mejoramiento de las condiciones habitacionales y de servicios básicos sanitarios para la población de la Margen sur de Río Grande.

Municipio de Rio Grande (2017) El nuevo modelo de gestión municipal en las políticas de hábitat de la ciudad de Río Grande. 2011-2016. Concurso reconocimiento a la buena gestión municipal. Municipio de Rio Grande - Tierra del Fuego.

Valdeiglesias, K. (2013) "Mejoramiento de las condiciones habitacionales y de servicios básicos sanitarios para la población de la Margen Sur de Río Grande, Provincia de Tierra del Fuego, República Argentina". Argentina. 